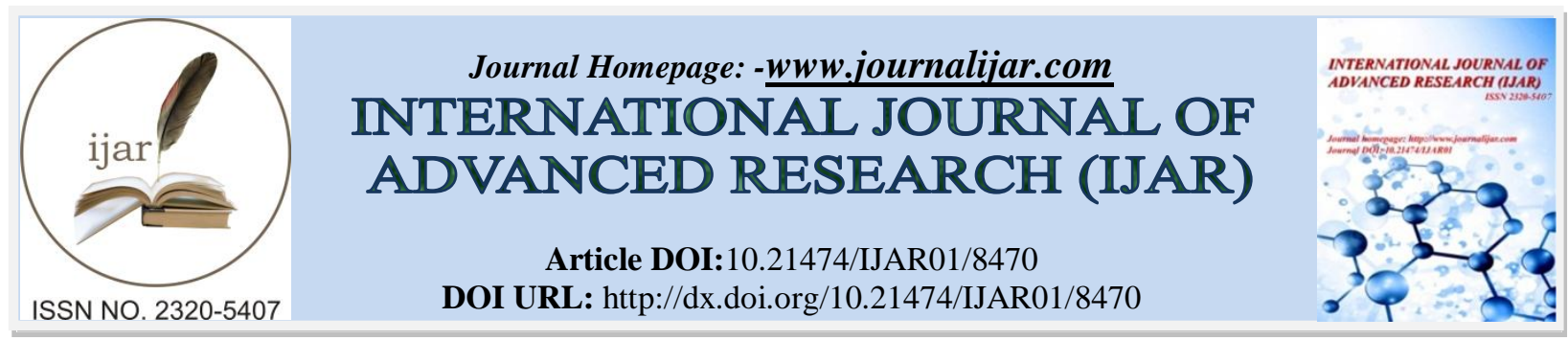

RESEARCH ARTICLE

\title{
NANOTECHNOLOGY IN WATER TREATMENT, CASE STUDY IN BANGALORE.
}

\author{
Ajay Kumar Sahu ${ }^{1}$, Prangya Paramita Acharya ${ }^{3}$, Barsha Rani Kar ${ }^{2}$, Rahul Nemani $^{1}$ and Manjunath Gowda ${ }^{1}$ \\ 1. Dept of Microbiology, Bangalore University, Bangalore. \\ 2. Dept of Biotechnology, Utkal University, Bhubaneswar. \\ 3. Dept of Biotechnology, Sambalpuruniversity, Odisha.
}

\section{Manuscript Info}

\section{Manuscript History}

Received: 02 December 2018

Final Accepted: 04 January 2019

Published: February 2019

Key words:-

Nanotechnology, waste water treatment, application of nanotechnology, Bangalore areas.

\begin{abstract}
Water shortages and lack to safe drinking water will continue to grown as major problems. One billion people access to safe drinking water and 3.4 billion people access to proper sanitation, increasing to access drinking water is the nanotechnology application could play an essential role in the solving this water by introducing effective and cheap waste water treatment techniques .the main aim of the paper is assess the applicability of using nanotechnology in waste treatment in Bangalore, the paper discusses the definition of nanotechnology and green nanotechnology application areas, the paper is defined the using impacts and risks of nanotechnology, then we defined the case study of Bangalore in using nanotechnology to solve the potential problems to solve the water problems ,the study concluded that although nanotechnology can help to solve the problems ,there is some challenge using nanotechnology, these challenge include technology ,market challenge and human health risk at Bangalore .waste water treatment is the process of converting waste water that is no longer needed or is no longer suitable for uses into bilge water that can be discharged back into the environment it is formed by a number of activities including bathing, washing, rainwater runoff.
\end{abstract}

Copy Right, IJAR, 2019,. All rights reserved.

\section{Introduction:-}

A small and inadequate amount of water, regarding both quality a critical threat o the current and future well being of people a particular to developing countries,sustainable water management is a vital side of solving the problems of poverty .safe drinking water is very important to the protection of human wellbeing, particularly among children, water related disease are the most common cause of skin disease, sickness, death among the poor in the developing areas.

According to world health Organization about $6 \%$ of the worldwide disease is related to water that infections diarrhea being the most components more than 4500 children under five year of age die every day from disease such diarrhea .

Access to safe water close to home will save amounts of the time that can be develop productive activities which basis of economic growth , lack access to water reduces the amounts of food available in both crops and live stocks and the quality.

Corresponding Author:-Ajay Kumar Sahu.

Address:-Dept of Microbiology, Bangalore university, Bangalore. 
Safe drinking water is worldwide issues and is predicted to increase with population growth and environment changes. There is need to investigate and exploration of new technologies for delivering clean drinking water.

\section{Nanotechnology:-}

Nanotechnology is the science of manipulating materials at very small sizes scale that is the most of atomic and molecular levels nanotechnology allows for the design the synthesis and controls at the length scale range of 1-100 $\mathrm{mn}$.

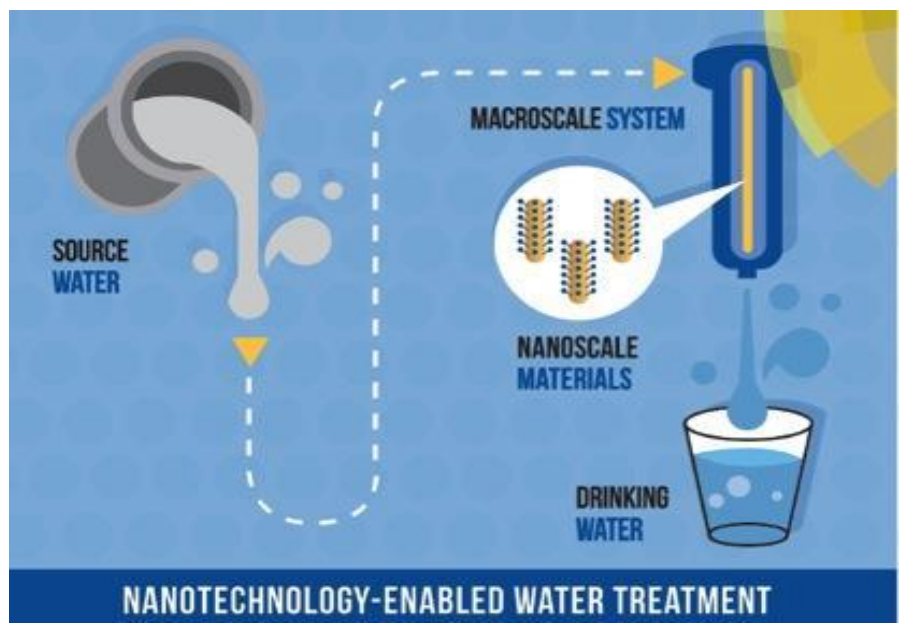

\section{Green Nanotechnology:-}

Green nanotechnology is the use of products and devices of nanotechnology to improve sustainability .green nanotechnology induces making green nano particles products in supports of sustainability.

And also called as the study of how nanotechnology can improves the environment for using of the less energy during the process production, the ability to recycle product after uses and using eco friendly materials.

The first dimension of the nano particles products that gives solution to environment difficulties, these green nanotechnology products are used to prevent harm from pollutants and are incorporate into the environmental technologies to prevent remediate hazardous waste sites.

\section{Application of green nanotechnology:-}

Nano absorbents like nano clay, metal oxide nanoparticles, nonporous carbon fibers and polymeric absorbents will eliminate particulates from contaminated water.

Nanotechnology gives the possibility to improve energy efficiency beyond all branches of industry and to economically advantage renewable energy production through new technological solutions and optimized in the energy productions.

\section{Energy usage:-}

\section{How it works???}
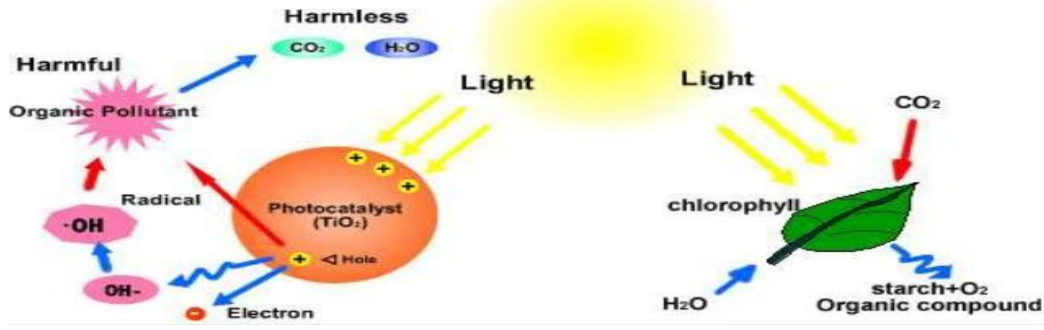
To accomplish sustainable energy supply and parallel to the statement improvement of the accessible energy sources, it is important to enhance the efficiency of energy uses and to avoid unnecessary energy consumption.

Nanotechnology gives a number of methodologies to save energy the reduction of the fuel consumption in automobiles through lightweight of materials on the basis of nanocomponents.

\section{Energy store:-}

The energy store can be in terms of nanotechnology for enhance to existing and nano enabled fuels cells.

\section{Nanotechnology in water treatment}

Water is the most important asset of human civilization and portable water supply is a basic human necessity, however the meeting of the global demands these problems will only increase with time.

Only $2.5 \%$ of the Worlds Ocean and seas harness fresh water, however $70 \%$ fresh water is frozen as internal ice only. Water treatment is must be implemented in these affected places, available technologies for water treatment are reaching their limits in providesufficient quality to meet human and environmental needs therefore reuses,recycle,repurpose are the needs of the day.

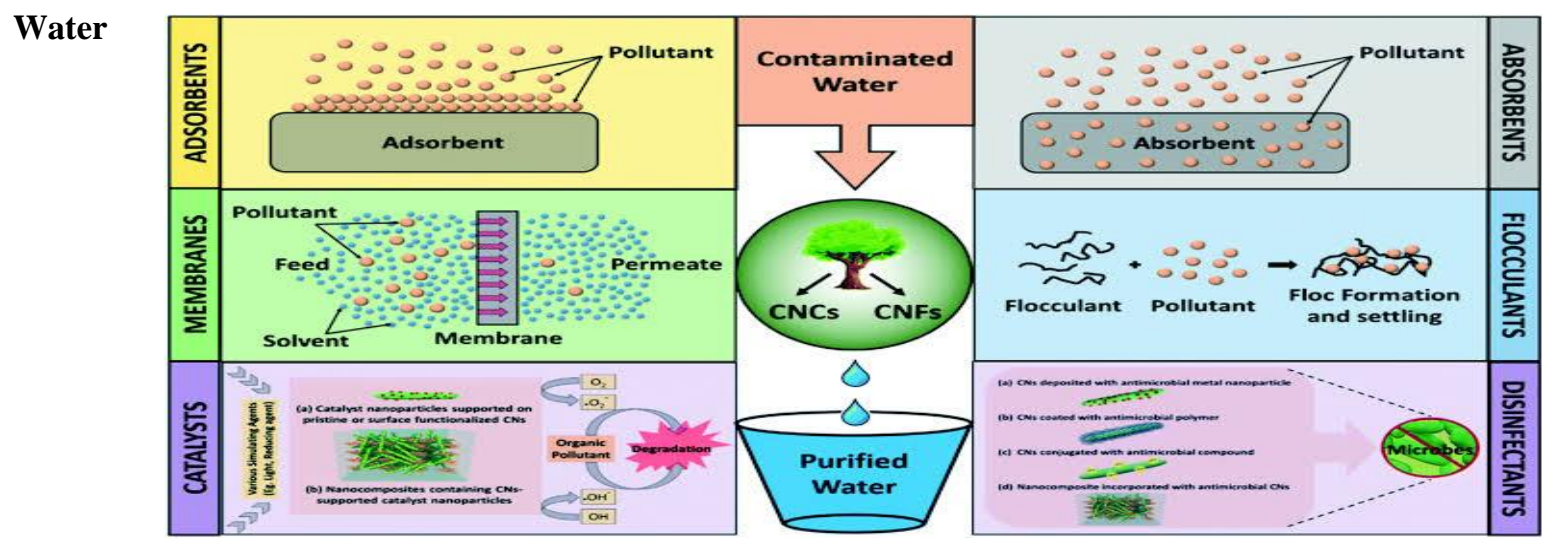

\section{purification:-}

Water purification using nanotechnology explore nanoscopic materials such as carbon nanotubes and alumina fibers for nanofiltration, the impurities that nanotechnology can tackle depends on the stage of the water purification to which the technique is applied.

There are plenty of water purifiers available in the market which use in its purest forms boiling, filtration,

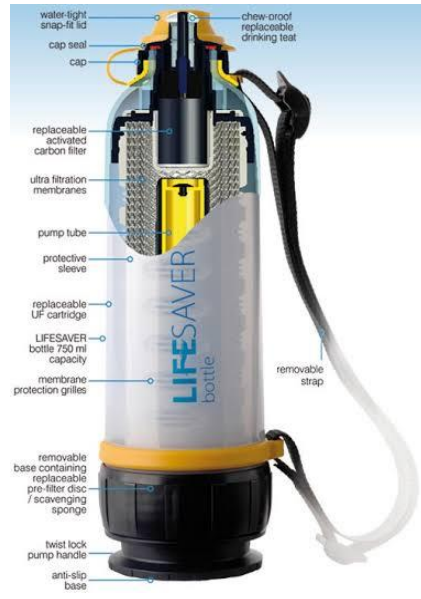

\section{How it works ???}

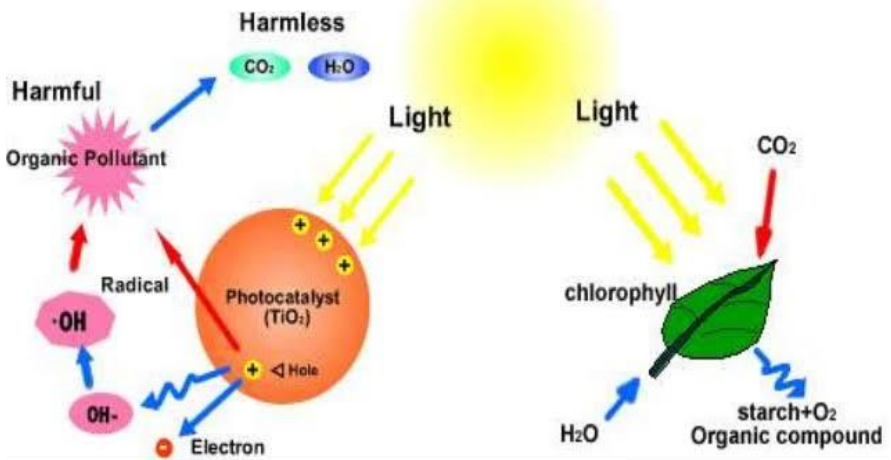




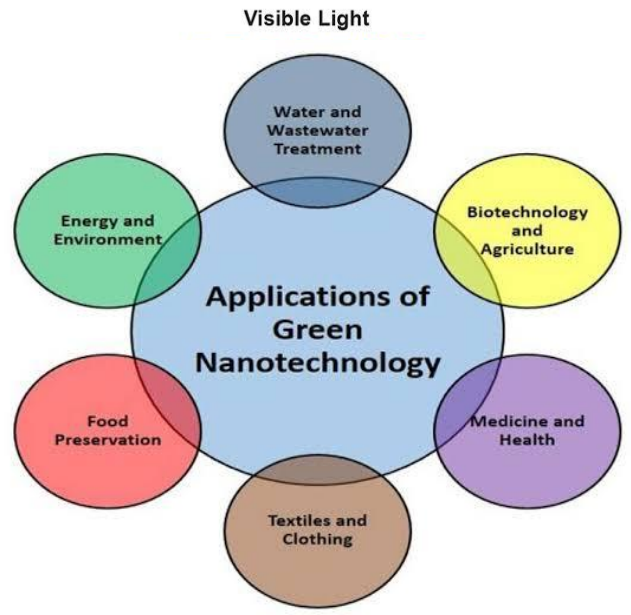

Fig. 17.7 Applications of green nanotechnology

Distillation, chlorination, sedimentation and oxidation:-

Currently nanotechnology plays a vital role in water purifications techniques, nano membrane are used with the purpose of softening the water and treatments and removal of containments such as physical, biological and chemical containments, there are variety of the techniques in nanotechnology which uses nano particles for providing safe drinking water with a high level of effectiveness. Some techniques have become commercialized.

For better water purification or treatment processes nanotechnology is preferred many different types of nanoparticles are used in water treatment processes. Nanotechnology holds great promise in remediation, desalination, filtrations, purification and water treatments.

The main features that makenanoparticles effective for water treatment are

1. Surface area

2. Small volume

3. The higher the surface area and volume, the particles become stronger, more stable and durable.

4. Materials may change electrical, optical, physical, chemical, or biological properties at the nano levels.

5. Makes chemicals and biological reactions easier.

Water purifiers using nanotechnology:-

The lifesaver bottle is designed so that it is very simple for its user to get clean water. It is a microbiological water filter that uses nanotechnology to filter out bacteria, viruses, parasites from contaminated water sources.

It can be used to collect water from the bottle is uncapped in order to fill it up, the bottle consist of a pump at its bottom, so once the bottle is full, it should be tightly closed and then pumped.

The pressure that builds up by pumping will makes the water to pass through the filter by purifying it, the bottles interchangeable filter can purify between $4 \mathrm{k}$ to $6 \mathrm{k}$ liters.

Life saver jerrycan is portable water purification system. It is commonly used for storage and purification purpose, the capacity of life saver jerrycan is 18.51 , it can filter out particles up to 0.015 microns.

\section{Life saver cubes:-}

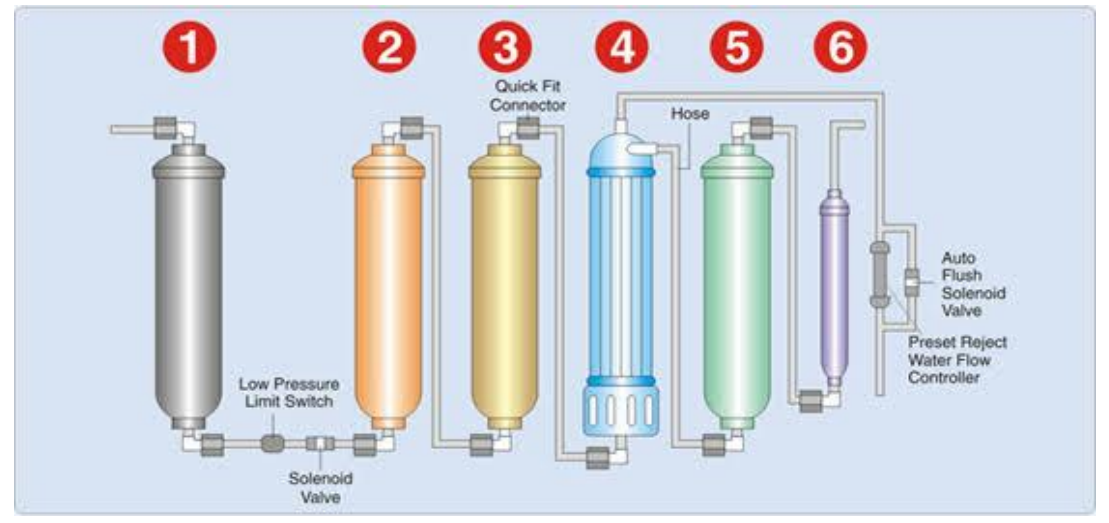


Life saver cubes is novel and portable water purifier which filter the contaminated water and provides clean water instantly and thus making it fit for drinking purpose. It is predominantly used as a household water purifier. It consists of a cube of 5 liter capacity and dirty water can be stored inside the cubes.

\section{Nanocream}

Nano cream is pleated filter cartridges are another types of sediments filter. They are designed in such a way that it could satisfy the difficulties in water treatment, water when multilayer is used, it is capable of retaining $99 \%$ of microbes.'

\section{Advantage of nanotechnology for water treatment}

Nanotechnology derived water filtration processes are much more efficient as compared to traditional techniques as these solutions can be fabricated with features that can be enhance the absorption of materials from water. Nanotechnology is highly effective alternative method to removing a wide range of contaminant from any type of water supply, despite their high specificity in eliminating certain contaminant, nano materials exhibits certain limitations, especially when considering the potential uptake of these materials into wildlife.

\section{Market for nanotechnology water treatment in Bangalore}

Market for nanotechnology products utilized in water treatment assessed at 1.54 billion in 2015 and will grow at compound annual growth at a compound annual growth rate of 9.8\%of estimation 2.5 billion in 2016.

A large portion of the current market is made up of established treatment products, reverse osmosis, nano filtration membrane module, which may be arranged as nanotech based the market for established products was nearly 1.4 billion in 2016.

Numerous emerging products like nano fiber, carbon nano tubes, range of nano particles are in the pre market phase. The market for the emerging products was 46 billion in 2016 and expected to reach 116 billion in 2018 at a compound annuals growth rate of $30 \%$.

\section{Impact of green nanotechnology}

In the process of producing and utilizing green nanotechnology products, additionally to direct impacts, there are also indirect impacts, like spillovers to third parties and various impacts on supply chains, impacts on the environment and energy utilization.

\section{Application of green nanotechnology in waste water treatment}

Deficiency of water threatens the improvement and the human security of many countries all over the world. It is the predicted that this problems could solved by emerge of nanotechnology in water treatment like water reusing, sea water desalination and water remediation more efficient and effective.

Waste water is any water that has been polluted by organic toxin, bacteria and microorganism, industrial effluent or any components that its natural quality.

\section{Water treatment types}

1. Nano filtration membrane these consider as a physical boundary and selectively dismiss substance smaller than their pores, thus remove harmful pollutant and retain useful nutrient present in water.

2. Nanocatalysts and magnetic nano particles may allow the utilization of heavy polluted water for drinking, sanitation and irrigation.

3. Nano sensor for the detection of contaminant for water purification would permits individual to more quickly discover what the more contaminant are without having to send sample to laboratories for testing.

\section{Benefits of using nanotechnology in water treatment}

1. Increased effectiveness contaminants could be more effectively removed, that were previously impossible to remove could now be removed, because the expand specificity of nanotechnology and the advancement of smart filter for particular utilization.

2. Simplification nanotechnology could radically reduce the number of step that is involved and materials or energy required for water treatment. 
3. Reduce cost significant introductory investment would be incorporate or switch to nanotechnology based water treatment, on the adopted these innovation could consider lower water treatment cool over the long term.

\section{$R$ and $D$ expenditures (GDP \%):-}

1. $2007-0.78 \%$

2. $2005-0.98 \%$

3. $2007-0.95 \%$

4. $2009-0.98 \%$

5. $2012-0.87 \%$

6. $2015-0.97 \%$

\section{Nanotechnology and water treatment in Bangalore}

Water resources in Bangalore are restricted to river, rainfall and flash flood, ground water in the desert area in Bangalore.

\section{Rainfall:-}

the average annual quality of successful used rainfall water is about 1.5 billion per year.

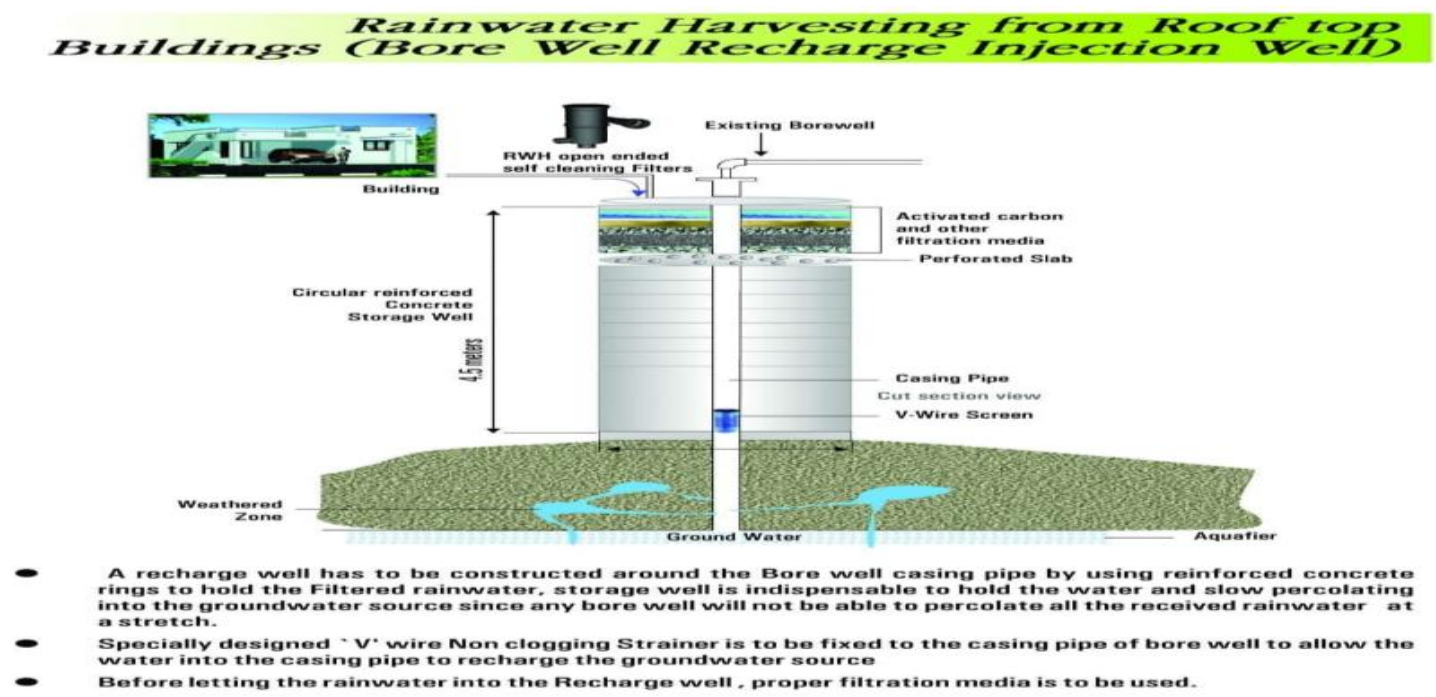

\section{Ground water:-}

the total amount of ground water has been estimated at around 30000.Although current abstraction is estimated to be 3.0 billion per year.

\section{Desalination:-}

sea water in Bangalore has been given below low priority as a water supply sources because high cost of water treatment.

\section{Domestic sewage -}

is being reused for irrigation with mixing with fresh water, it is assessed that aggregate amount of reused treated water in Bangalore.

Rainfall - 1.5

Ground water -3.5

Water supply in Bangalore - 48.5

\section{Water demand in Bangalore:-}

1. municipal-10

2. industrial -2.7

3. agricultural -76

4. Water demand in Bangalore -88.7 
The water sector in Bangalore is facing several problems and difficulties in both quantity and quality, Bangalore suffer from water shortage and deterioration of water quality.

\section{Technologies used in water treatment:-}

1. availability of high skilled workers

2. availability of operation and maintenance finance

3. up flow anaerobic sludge blanket

4. specific tank

5. stabilization ponds

6. in stream wetland system

7. rotating biological contactor

\section{Challenges in using nanotechnology to safe water}

1. Nanotechnology for water treatment is beginning science, there is requirement for consider s measure work before it might be mainstreamed in products.

2. There is a lack of problems for investment of water treatment exploration of innovation.

3. There is a lack of stress on the incubation stage that enables research nd proven technologies to end up to be marketable products.

4. Water is seen as free products. It is generally nature provides subsequently the willingness to pay for water treatment is extremely restricted.

5. The impacts of these materials on biological systems should be seriously addressed to water treatment.

6. Nano membrane plants can be built as portable units, which can be assembled in urban area of Bangalore.

\section{Water Treatment Company in Bangalore:-}

1. New water technologies

2. Indian ion exchange andchemicals

3. Aqua $\mathrm{p}$ zone enterprise

4. Bisineer sales marketing of water

5. Voda matrix system of water

6. Spectrum engineering works

\section{Reverse osmosis process:-}

REVERSE OSMOSIS

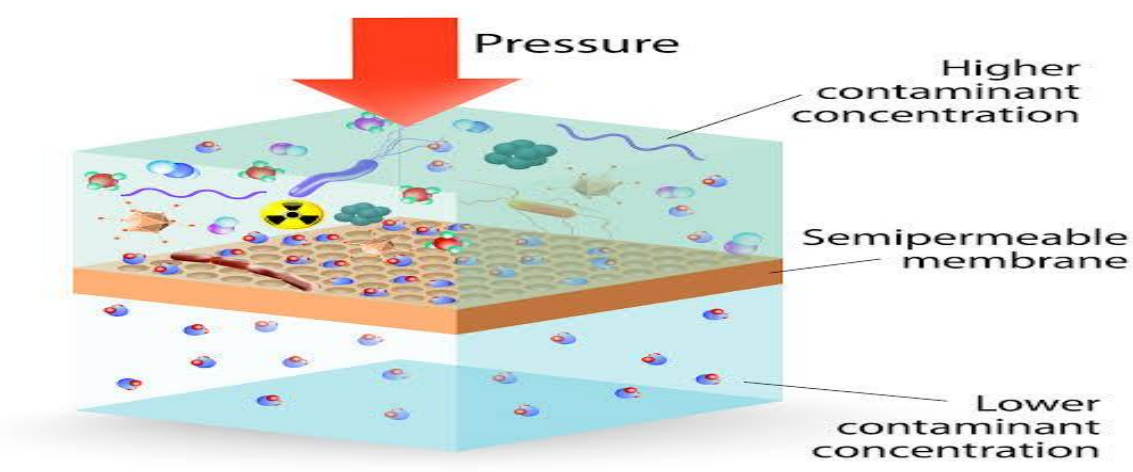

Reverse osmosis technology is the most widely used methods for water purification across various industriesIt involves pushing of water through a semi permeable membrane which blocks impurities and release purified water for consumption.

All system supplied with convenience feature and parts including high flow tubing, tank to faucet, quick connect fitting integral shut off, high capacity membrane and more. 
Reverse osmosis is a water purification technology that uses a semi permeable membrane to remove ions molecular and larger particles from drinking water

\section{Benefits of reverse osmosis:-}

1. Eliminates sodium

2. Removes leads

3. Lower energy costs

4. Take up very little space

5. Easy to maintains water treatment

6. Produces better testing water

7. Release bottle water with purify.

\section{Conclusion:-}

The study of the experience of growing scarcity of fresh water resources in Bangalore. Nanotechnology revolution can play essential role in solving the problems of rising demand of clean water and decrease of the available supplies of fresh water

The future markets for nanotechnology based water treatment must be take accounts of the risks and opportunity.

We conclude that nanotechnology is a promising solution to water crisis, this solution faces some challenge, the most important one is the risk associated with nano materials on human health, other challenges are the most cost getting nanotechnology of lab scale.

\section{Reference:-}

1. Sustainability of water publication based on nanotechnology, international journal of sustainability, volume3.

2. P karn and lynnl. Bergeson 2009, green nanotechnology, natural resources and environment, volume 23.

3. Nanotechnology in water treatment, report by bcc research council of European union 2007.

4. I j elsalibyetal (2003), nanotechnology for waste treatment in brief, water and waste treatment technologies.

5. Lusiafillpoonoi and Duncan Sutherland (2007) application of nanotechnology, environment, nanotechnology capacity building NGOS.

6. Mcderost (2004) nanotechnology patent literate review.

7. The impact of nanotechnology on companies, policy insights from case studies republic of south Africa, national nanotechnology strategy.

8. Mihailroco( 2009) the long view of nanotechnology development, the national nanotechnology initiative at 5 years.

9. Ministry of water resources and irrigation (2014) water treatment in Bangalore, the urgent need for regional cooperation among basin countries.

10. Meridian institute (2014), nanotechnology of waste water treatment national nanotechnology resources.

11. MohyEIdinomar and rifaatabdelwahaab, waste reuse in Bangalore, opportunities and challenges.

12. Naglaa Mohamed (2010) reuse of waste water treatment in region, Bangalore, karnatak.

13. NFR (2013) nanotechnology and waste water, science and technology, republic of south Africa.

14. UN (2013) the millennium development goals report 2014.

15. Thembelahille and etal (2013) nanotechnology, water treatment and development, merdian institute. 